\title{
ANALYSIS OF FACTORS ASSOCIATED WITH DELAYED GASTRIC EMPTYING AFTER WHIPPLE'S PROCEDURE
}

\author{
Talha Yasin, Nasir Mehmud Wattoo, Qasim Butt, Kamran Safdar, Muhammad Asif* \\ Pak Emirates Military Hospital/National University of Medical Sciences (NUMS) Rawalpindi Pakistan, *Combined Military \\ Hospital/National University of Medical Sciences (NUMS) Rawalpindi Pakistan
}

\begin{abstract}
Objective: To assess the frequency and analyze associated factors of delayed gastric emptying among the patients undergoing Whipple's procedure at surgical unit of a tertiary care centre in Pakistan.

Study Design: Cross sectional study.

Place and Duration of Study: Pak Emirates Military Hospital and Combined Military Hospital Rawalpindi, Pakistan, Apr 2018 to Mar 2019.

Methodology: A prospective study was conducted on 80 patients of both the genders who underwent Whipple's procedure at the surgical unit of abovementioned hospitals. Delayed gastric emptying was diagnosed based on the criteria as defined by the International Study Group of Pancreatic Surgery by the consultant surgeons involved. Factors studied in our analysis included age, gender, smoking, presence of co morbidities, peroperative blood transfusion, sepsis, operative time and BMI.

Results: Out of 80 patients included in the final analysis, 61 (76.25\%) were male and $19(23.75 \%)$ were female. Mean age of patients included in our study was $46.31 \pm 6.711$ years. Thirty six (45\%) patients had delayed gastric emptying while $44(55 \%)$ did not meet the criteria as mentioned above. With binary logistic regression we found that presence of sepsis and high BMI had a strong relationship ( $p$-value $<0.05)$ with delayed gastric emptying after the Whipple's procedure.

Conclusion: Delayed gastric emptying is a fairly common phenomenon among the patients undergoing Whipple's procedure. High BMI and post-operative sepsis constitute the group which is at the highest risk of developing this post-operative complication in our study.
\end{abstract}

Keywords: Gastric emptying; risk factors, Whipple's operation.

This is an Open Access article distributed under the terms of the Creative Commons Attribution License (http://creativecommons.org/licenses/by/4.0), which permits unrestricted use, distribution, and reproduction in any medium, provided the original work is properly cited.

\section{INTRODUCTION}

Cancers involving the pancreatic region and gastro-intestinal tract have been on a rise in the last decade in all parts of the world including the developing countries ${ }^{1}$. Various treatment regimens and modalities have been used to treat such patients. Chemotherapy, radiation therapy and immune therapy are some of the non-invasive methods used in the management of such patients ${ }^{2}$. Despite all these medical methods, surgical excision remains the mainstay of treatment in these patients ${ }^{3}$. In most cases it may be the first line of treatment after the diagnosis and has a role in both curative and palliative management of the malignancies of this region ${ }^{4}$. Surgical

Correspondence: Dr Talha Yasin, Army Liver Transplant Unit, Pak Emirates Military Hospital, Rawalpindi Pakistan

Received: 03 Jun 2019; revised received: 02 Oct 2019; accepted: 08 Oct 201.9 oncology and hepatobiliary surgery is an emerging specialty in our part of the world with very limited number of institutes in the country offering experience and training in this area due to a limited number of foreign trained surgeons who are able to provide their expertise in the field ${ }^{5}$.

A lot of work has been done regarding the delayed gastric emptying after surgeries involving the pancreas and adjacent organs. Due to complex anatomy of this region including various vital organs, ducts, lymph nodes, vessels and nerve plexus, a surgeon has to be extra cautious while approaching this region for any kind of intervention, specially a difficult and demanding procedure like Whipple's, to avoid untoward outcomes. Whipple's procedure has been notorious in terms of high morbidity and mortality around the globe 6 . Delayed gastric emptying has also 
been a fairly common complication among the patients undergoing this surgery. A study done in United States of America found that around $20 \%$ of the patients undergoing Whipple's pancreaticoduodenectomy or related surgeries developed the complication of delayed gastric emptying. Post-operative sepsis emerged as an independent risk factor linked with the presence of this complication ${ }^{7}$. Similar study done in Sweden showed this prevalence to be double as compared to the previously cited US study. Around $40 \%$ of the Swedish study cohort had delayed gastric emptying after the surgical procedures involving the pancreas and duodenum, especially elderly population ${ }^{8}$. Another recent study showed statistically significant negative impact of high body mass index and increased operating time on delayed gastric emptying among the target population 9 .

It must be kept in mind that the longer this condition persists, the higher the chances of severe electrolyte imbalances secondary to excessive vomiting, malnutrition, risk of re-feeding syndrome, dehydration associated renal injury, bezoars formation, stomach obstruction and life threatening multi-organ dysfunction ${ }^{10}$.

If complications occur, they can lead to longer hospital stays and increased requirement of health care support, have a significant impact on our overall resource utilization and provision of standard quality of care to all ${ }^{11}$. A study done in past has revealed that overall morbidity associated with Whipple's procedure in our setup is around $54 \%$ with a mortality of $10 \%$ which is an alarmingly high figure when compared to international data ${ }^{12}$. We, therefore, planned this prospective study at our center with the rationale to look at the frequency of delayed gastric emptying and associated risk factors among the patients undergoing Whipple's pancreaticoduodenectomy and in future assess its impact on our health care resources.

\section{METHODOLOGY}

This prospective cross-sectional study was conducted at the surgical departments of Pak-
Emirates Military Hospital and Combined Military Hospital Rawalpindi in liaison with the oncology department, from April 2018 to March 2019. Sample size (>90 participants) was calculated by WHO Sample Size Calculator by using the statistics of study of Parmar et al. With reference percentage of $65 \%^{7}$. Non probability consecutive sampling technique was used to gather the sample. All patients between the age of 18-65 years who underwent Whipple's procedure for any malignancy of this region were included in the study. Patients who were referred from other military, public sector and private hospitals and were operated upon at our center were also included in the analysis in addition to the patients of the above said hospitals. Exclusion criteria was the patients who were under 18 years of age, had recent history of substance misuse or preoperative gastro paresis.

After ethical approval from the ethical review board committee (IRB letter No. PEMH/ A/0218) and written informed consent from potential participants, patients who underwent Whipple's surgery and met the inclusion criteria as defined above were included in the study. Routine analgesia and antibiotic cover was given to each patient as per the hospital protocol. Delayed gastric emptying was defined according to the International Study Group of Pancreatic Surgery as the need for gastric decompression for 7 days post-operatively or the absence of oral in take by post-operative day $14^{13}$. Patients were kept admitted as per routine procedure and called for follow up if discharged earlier than 14 days and routine TPN was given to all as per protocol. Factors studied in our analysis of delayed gastric emptying were age, gender, presence of co-morbidities, per-operative blood transfusion, sepsis, smoking, operative time and body mass index. A special proforma was designed for this study including the socio demographic profile and all the pre-defined risk factors included in the study.

All statistical analysis was performed by using the Statistics Package for Social Sciences version 24.0 (SPSS-24.0). Patients were divided 
into two categories i.e. patients with delayed gastric emptying and patients without delayed gastric emptying. Age, gender, body-mass index, history of smoking, presence of co morbidities, per-operative blood transfusion, operating time and post-operative sepsis were compared in both the groups with and without the delayed gastric emptying by using the chi-square test and binary logistic regression. Risk factors were considered as significantly linked with the delayed gastric emptying if $p$-value was less than or equal to 0.05 .

\section{RESULTS}

A total of 83 patients were initially approached to be enrolled in the study. One patient was above 65 years of age, one had pre-operative gastroparesis and one had history of recent opiate use. Out of the 80 patients included in the final analysis, $61(76.25 \%)$ were male and 19 (23.75\%)

Table I: Assocition of the study groups and application of chi-square test.

\begin{tabular}{|c|c|c|c|}
\hline $\begin{array}{l}\text { Socio } \\
\text { Demographic } \\
\text { Factors } \\
\text { Total }\end{array}$ & $\begin{array}{l}\text { No Delayed } \\
\text { Gastric } \\
\text { Emptying } \\
\text { n }(\%) \\
44(55)\end{array}$ & $\begin{array}{c}\text { Delayed } \\
\text { Gastric } \\
\text { Emptying, } \\
\text { n (\%) } \\
36(45)\end{array}$ & $\begin{array}{c}p- \\
\text { value }\end{array}$ \\
\hline \multicolumn{4}{|l|}{ Age } \\
\hline $\begin{array}{l}<30 \text { year } \\
30-65\end{array}$ & $\begin{array}{l}18(40.9) \\
26(59.1)\end{array}$ & $\begin{array}{l}19(52.7) \\
17(47.3) \\
\end{array}$ & 0.289 \\
\hline \multicolumn{4}{|l|}{ Gender } \\
\hline $\begin{array}{l}\text { Male } \\
\text { female }\end{array}$ & $\begin{array}{l}30(68.2) \\
14(31.8)\end{array}$ & $\begin{array}{l}31(86.1) \\
05(13.9)\end{array}$ & 0.061 \\
\hline \multicolumn{4}{|c|}{ Presence of Comorbidities } \\
\hline $\begin{array}{l}\text { No } \\
\text { Yes } \\
\end{array}$ & $\begin{array}{l}29(65.9) \\
15(34.1) \\
\end{array}$ & $\begin{array}{l}20(55.5) \\
16(44.5) \\
\end{array}$ & 0.345 \\
\hline \multicolumn{4}{|l|}{ Sepsis } \\
\hline $\begin{array}{l}\text { No } \\
\text { Yes }\end{array}$ & $\begin{array}{c}4(93.2) \\
03(6.8)\end{array}$ & $\begin{array}{l}24(66.6) \\
12(33.4) \\
\end{array}$ & 0.002 \\
\hline \multicolumn{4}{|c|}{ Per-Operative Blood Transfusion } \\
\hline $\begin{array}{l}\text { No } \\
\text { Yes }\end{array}$ & $\begin{array}{l}39(88.6) \\
05(11.4)\end{array}$ & $\begin{array}{l}30(83.3) \\
06(16.7)\end{array}$ & 0.494 \\
\hline \multicolumn{4}{|l|}{ BMI } \\
\hline $\begin{array}{l}<30 \\
30 \text { or more }\end{array}$ & $\begin{array}{c}43(97.7) \\
01(2.3) \\
\end{array}$ & $\begin{array}{l}24(66.6) \\
12(33.4)\end{array}$ & $<0.001$ \\
\hline \multicolumn{4}{|l|}{ Smoking } \\
\hline $\begin{array}{l}\text { No } \\
\text { Yes }\end{array}$ & $\begin{array}{l}38(86.3) \\
06(13.7)\end{array}$ & $\begin{array}{l}28(77.7) \\
08(22.3)\end{array}$ & 0.316 \\
\hline \multicolumn{4}{|l|}{ Operative Time } \\
\hline $\begin{array}{l}<5.5 \text { hours } \\
>5.5 \text { hours }\end{array}$ & $\begin{array}{l}35(77.2) \\
09(22.8)\end{array}$ & $\begin{array}{l}28(77.7) \\
08(22.3)\end{array}$ & 0.848 \\
\hline
\end{tabular}

were female. Male to female ratio was 3.2:1. Mean age of patients who underwent the procedure was $46.31 \pm 6.711$ years. $36(45 \%)$ patients had delayed gastric emptying while 44 (55\%) did not meet the criteria for delayed gastric emptying as defined above. Other characteristics of the patients have been summarized in table-I along with the application of chi-square. Table-II shows that with binary logistic regression, presence of sepsis and high BMI had a strong relationship ( $p$-value $<0.05)$ with delayed gastric emptying after the Whipple's procedure. With binary logistic regression we found that presence of sepsis and high BMI had a statistically significant relationship with delayed gastric emptying after the Whipple's procedure $(p$-value $<0.05)$ (table-II).

Table-II: The correlated factors relating to the type of modality used among the patients suffering from peri-pancreatic accumulation after acute pancreatitis: the binary logistic regression analysis.

\begin{tabular}{l|c|c|c|c}
\hline & $\begin{array}{c}p- \\
\text { value }\end{array}$ & $\begin{array}{c}\text { Odds } \\
\text { ratio }\end{array}$ & \multicolumn{2}{|c}{$\begin{array}{c}\text { Confidence } \\
\text { Interval }\end{array}$} \\
\cline { 4 - 5 } & Lower & Upper \\
\hline $\begin{array}{l}\text { Age (ref. is 30 } \\
\text { years or less) }\end{array}$ & 0.806 & 0.871 & 0.290 & 2.619 \\
\hline $\begin{array}{l}\text { Per-operative } \\
\text { blood transfu- } \\
\text { sion (reference is } \\
\text { no transfusion) }\end{array}$ & 0.352 & 2.380 & 0.384 & 14.760 \\
\hline $\begin{array}{l}\text { Gender (ref. is } \\
\text { male) }\end{array}$ & 0.149 & 0.358 & 0.089 & 1.443 \\
\hline BMI (ref. is <30) & 0.021 & 13.978 & 1.477 & 132.290 \\
\hline $\begin{array}{l}\text { Presence of } \\
\text { comorbidities } \\
\text { (ref. is no } \\
\text { comorbidity) }\end{array}$ & 0.636 & 1.315 & 0.423 & 4.091 \\
\hline $\begin{array}{l}\text { Sepsis (Ref. is no } \\
\text { Sepsis) }\end{array}$ & 0.012 & 9.373 & 1.619 & 54.262 \\
\hline $\begin{array}{l}\text { Smoking (Ref. is } \\
\text { no smoking) }\end{array}$ & 0.366 & 2.138 & 0.411 & 11.114 \\
\hline $\begin{array}{l}\text { Operative time } \\
\text { Ref. is <5.5 } \\
\text { hours) }\end{array}$ & 0.211 & 0.322 & 0.055 & 1.898 \\
\hline
\end{tabular}

\section{DISCUSSION}

Illiac et al, had concluded in their analysis that pancreas and related structures have been fairly common sites for malignancies ${ }^{14}$. Prognosis is usually mixed and not very good in the under- 
developed countries ${ }^{15}$. Reasons for this may be the aggressive nature of the disease, delay in diagnosis and increased morbidity associated with complex and extensive surgical procedure. In our hospital we do 100 to 120 Whipple's pancreaticoduodenectomies a year as it is a tertiary care hospital with all available resources, expertise and a large catchment area. Given the nature of our health care system with no primary prehospital medical centres feeding into the tertiary hospital systems, it is next to impossible to follow the patients for a long period of time unless patients themselves put an effort into attending all follow-up visits, hence, most of our patients get lost to follow up.

Cancers of pancreas usually involve a multidisciplinary team approach with oncologists, radiation therapists and hepato-biliary surgeons with special interests in pancreatic surgery. Chemical and radiation therapy not only immunesuppress the patients but also make them nutritionally deplete thus increasing their risk of developing complications in the intra and post-operative period, therefore, advance multidisciplinary planning is of utmost importance in this cohort. Patients who received neo-adjuvant therapy were deemed high risk for developing intra-operative complications compared to those who did not. There was limited local data available for comparison to estimate the number of patients developing delayed gastric emptying post Whipple's procedure and its associated risk factors in these patients. This study was therefore planned to look into this phenomenon associated with Whipple's procedure in patients with a malignant pathology.

Around 80 patients underwent this procedure in our department during the period of ten months. Out of them $45 \%$ developed delayed gastric emptying. These results were found to show very slightly higher incidence compared to the existing literature on this subject by Parmer et al, and Robinson et al, in 2013 and 2015 respectively ${ }^{7-}$ 9. Reasons for this slight higher incidence of delayed gastric emptying in our study may include lack of surgical oncology facilities or a slightly sub-standard post-operative nutritional care due to lack of dietician and nutritionist support in our system as compared to the developed countries.

Post-operative sepsis was also seen to be strongly linked to delayed gastric emptying in our study. This finding has been well documented in other studies in a 2015 study and also in study of Nguyen et al, in 20077,17, Wound infections and/or infection and breakdown of the surgical anastomosis can be one of the causes of this. Sepsis induced immunochemical changes in the body reduce immunity, slow down tissue healing, push the body into a catabolic state and depleting energy reserves thus inducing delayed gastric emptying. Both sepsis and delayed gastric emptying seemed to be interlinked with one driving the other and therefore it is difficult to say which is the cause and which is the effect and the onset of one can induce the other. Strict control of infection and involvement of a multidisciplinary team including microbiologists for judicious use of antibiotics may help reduce the chances of sepsis after the surgery.

As discussed earlier, delayed gastric emptying is a commonly occurring, serious but easily treatable post-operative complication of major surgeries and must be recognized well in time to avoid its life threatening sequelae. Nausea and vomiting may be early signs of this complication and should not be ignored in patients with recent major surgery. Nassar et al, has discussed this phenomenon in their study ${ }^{16}$. If unrecognized and untreated for a long time, this complication may lead to considerable distress and burden on the health budget as well. Therefore, the importance of educating the surgical and allied teams including the nursing staff and junior trainees about this complication and it's effective and timely management can not be stressed enough.

An interesting finding in our analysis was the increased chances of obese and overweight people developing the complication of delayed gastric emptying after Whipple's surgery. Though a lot of research has not been done in this regard but still the available limited studies by 
Noorani et al, and Camilleri et al, have supported this finding 8,18 . Reasons for this might be difficult surgical access, prolonged surgical time compared to lean patients, or overall compromised cardio-respiratory status of the individuals with raised BMI. More research is needed in this area to confirm the link between obesity and delayed gastric emptying specifically as obesity is a common public health problem in all parts of the world.

Parmer and colleagues have shown a strong link between co-morbid conditions including diabetes, hypertension and ischemic heart disease and gastroparesis after Whipple's procedure? Robinson et al, also had similar results ${ }^{9}$. Results of our analysis did not support the association. Further studies may look into this parameter in detail.

\section{LIMITATION OF STUDY}

One of the major limitations in generalizing the results of this study has been the study design and sample size. Cross-sectional study design is not an ideal design if definitive results are required for generalizing to a larger population. Sample was drawn from a military hospital which also reduces the chances of vast majority of general public to get included, thereby, skewing the results in the study. Relationship with type of tumor or underlying illness was not observed in this study. Drugs used in chemotherapy may affect the outcome in certain patients and need to be studied separately. Medication profile was not included and cases with neo-adjuvant chemotherapy treatment were not separated at the start of the study, therefore, difference between neoadjuvant and adjuvant chemotherapy patient outcomes can not be discussed here. Future studies with better design addressing all these limitations may generate more accurate results which may be applied to the majority of country's population.

\section{CONCLUSION}

Delayed gastric emptying is a fairly common phenomenon among the patients undergoing Whipple's procedure. High BMI and post-ope- rative sepsis constitute the group which is at the highest risk of developing this post-operative complication in our study.

\section{CONFLICT OF INTEREST}

There is no conflict of interest to be declared by any author.

\section{REFERENCES}

1. Saad AM, Turk T, Al-Husseini MJ, Abdel-Rahman O. Trends in pancreatic adenocarcinoma incidence and mortality in the United States in the last four decades; a SEER-based study. BMC Cancer 2018; 18(1): 688-71.

2. Mc Guigan A, Kelly P, Turkington RC, Jones C, Coleman HG, Mc Cain RS. Pancreatic cancer: A review of clinical diagnosis, epidemiology, treatment and outcomes. World J Gastroenterol 2018; 24(43): 4846-61.

3. Ansari D, Gustafsson A, Andersson R. Update on the manage-ment of pancreatic cancer: surgery is not enough. World J Gastroenterol 2015; 21(11):3157-65.

4. Hall BR, Cannon A, Atri P. Advanced pancreatic cancer: a metaanalysis of clinical trials over thirty years. Oncotarget 2018; 9(27): 19396-05.

5. Saletti P, Sanna P, Gabutti L, Ghielmini M. Choosing wisely in oncology: necessity and obstacles. ESMO Open 2018; 3(5): e000382.

6. Cusworth BM, Krasnick BA, Nywening TM, Woolsey CA, Fields RC, Doyle MM. Whipple-specific complications result in prolon-ged length of stay not accounted for in ACS-NSQIP Surgical Risk Calculator. HPB (Oxford) 2016; 19(2): 147-53.

7. Parmar AD, Sheffield KM, Vargas GM, Pitt HA, Kilbane EM, Hall BL. Factors associated with delayed gastric emptying after pancreaticoduodenectomy. HPB (Oxford) 2013; 15(10): 763-72.

8. Noorani A, Rangelova E, Del Chiaro M, Lundell LR, Ansorge C. Delayed gastric emptying after pancreatic surgery: analysis of factors determinant for the short-term outcome. Front Surg 2016; 3(1): 25.

9. Robinson JR, Marincola P, Shelton J, Merchant NB, Idrees K, Parikh AA. Peri-operative risk factors for delayed gastric emptying after a pancreaticoduodenectomy. HPB (Oxford) 2015; 17(6): 495-01.

10. Waseem S, Moshiree B, Draganov PV. Gastroparesis: current diagnostic challenges and management considerations. World J Gastro 2009; 15(1): 25-37.

11. Ittefaq $M$, Iqbal A. Digitization of the health sector in Pakistan: challenges and opportunities to online health communication: A case study of MARHAM social and mobile media. Digit Health 2018; 4(1): 2055207618789281.

12. Pal KMI, Bari H, Nasim S. Pancreaticoduodenectomy: A deve-loping country perspective. J Pak Med Assoc 2011; 61(3): 232-35.

13. Panwar R, Pal $\mathrm{S}$. The international study group of pancreatic surgery definition of delayed gastric emptying and the effects of various surgical modifications on the occurrence of delayed gastric emptying after pancreatoduodenectomy. Affiliations 2017; 16(4): 353-63.

14. Ilic M, Ilic I. Epidemiology of pancreatic cancer. World J Gastroenterol 2016; 22(44): 9694-05.

15. Wong MCS, Jiang JY, Liang M, Fang Y, Yeung MS, Sung JJY. Global temporal patterns of pancreatic cancer and association with socioeconomic development. Sci Rep 2017; 7(1): 3165.

16. Nassar Y, Richter S. Gastroparesis in non-diabetics: associated conditions and possible risk factors. Gastroenterol Res 2018; 11(5): 340-45.

17. Nguyen NQ, Ng MP, Chapman M, Fraser RJ, Holloway RH. The impact of admission diagnosis on gastric emptying in critically ill patients. Crit Care 2007; 11(1): R16.

18. Camilleri M, Malhi H, Acosta A. Gastrointestinal Complications of Obesity. Gastroenterol 2017; 152(7): 1656-70. 